\title{
Engagement Resources in Diplomatic Discourse: With Reference to Remarks by Chinese Foreign Ministry Spokesperson
}

\author{
Wu Hanfan \\ Department of Foreign Language, University of Shanghai for Science and Technology, Shanghai, China
}

\begin{abstract}
The statement made by a Foreign Ministry spokesperson at a regular press conference is a window for the world to understand China and its foreign policy on the one hand, and a sign expressing the Chinese position and attitude towards the events at home and abroad on the other hand. From the perspective of the appraisal theory, this paper reveals how the spokesperson employs the engagement resources to expand or contract the dialogue space to convey the Chinese stance to the audience. Through both quantitative and qualitative methods, it is found that even though dialogic expansion resources are chosen in preference by the spokesperson, all kinds of engagement resources integrate with each other to help the spokesperson negotiate their dialogic space with the audience.
\end{abstract}

Keywords: engagement resources, appraisal theory, Foreign Ministry spokesperson, attitude, stance

\section{Introduction}

The establishment of the Foreign Ministry spokesperson is a sign of the improvement of China's diplomatic system. When the system was first established, there were neither questions nor answers at press conferences. Now, the Foreign Ministry spokesperson's regular press conference not only releases information on important diplomatic activities, but also answers reporters' questions on major issues at any time. The questions raised by Chinese and foreign journalists at press conferences reflect the concern of the media and even the public on issues related to China's diplomacy. The answers given by the spokesperson at the press conference were formal and authoritative statements on the Chinese government's position. The spokesperson's statements on major or sensitive issues and his answers to reporters' questions became the basis for major media reports on China's policies (Zhang \& Li, 2017). Therefore, the news released and the questions answered by the Foreign Ministry spokesperson at the regular press conference are not only a window for the outside world to understand China's foreign policy and diplomacy, but also an important channel for the Chinese people to understand the Chinese government's position and views on international issues and foreign policy. By studying the discourse of the spokesperson and the discourse of the spokesperson quoted by the western media, it is found that there is no correlation between the attitude of the Chinese spokesperson and the attitude quoted by the western media ( $\mathrm{Wu}, 2011)$. It is believed that in order to enhance the effect of the Chinese voice, we should pay attention to "what to say", and furthermore pay attention to "how to say". This paper intends to

Wu Hanfan, Bachelor's degree, MA Candidate Department of Foreign Language, University of Shanghai for Science and Technology, Shanghai, China. 
use the engagement system of appraisal theory and AntConc analysis software to investigate the engagement resources in the regular press conference held in 2019, and to explore how the spokespersons use these resources to open and contract negotiation space with the audience so that they can swear and disseminate their attitudes and stance.

\section{Theoretical Framework and Method}

Appraisal theory, proposed by Martin and White, was developed from the interpersonal system of systemic functional grammar. It is applied to discourse analysis. Martin \& Rose (2002) assessed that appraisal theory is the development of interpersonal meaning at the lexical and semantic level, aiming at exploring, describing, and revealing how writers/speakers determine their stances, evaluate their attitudes, construct their roles, and negotiate their relationships through language resources in communication, so as to form alliances with readers/listeners with similar viewpoints and alienate or repel those with different viewpoints, ultimately achieving the goal of communication. Martin \& White (2005) divided appraisal theory into three systems: “attitude”, "graduation”, and "engagement”, each of which can be divided into different sub-systems. Attitude is concerned with our feelings, including emotional reactions, judgements of behaviour, and evaluation of things (Martin \& White, 2005). Attitude is divided into three regions of feeling including "affect”, "judgment”, and "appreciation". "Affect" is the language user's innate expression resources, which is expressed physiologically. It is concerned with registering positive and negative feelings. "Judgement” deals with attitudes towards behaviour, which we admire or criticise, praise, or condemn. "Appreciation" is the aesthetic aspects of texts, processes, and phenomena, expressing our evaluation of what is produced or presented, or of natural phenomena. Graduation is a classification of evaluation based on intensity, including two sub-categories of force and focus. The former category is divided into "raise" (e.g. most dangerous) and "low" (e.g. a little upset) according to the degree of strength or amount. The latter is divided into "sharpen" (e.g. a fully-fledged) and "soften" (e.g. about 10 years old) according to the prototypical nature and degree of accuracy of the category.

Martin's engagement system of appraisal theory is influenced by the former Soviet Union linguists Bakhtin and Voloshinov's academic theory. White (2003) defined engagement as the way texts can be seen to negotiate meanings with actual and potential audiences. The engagement system is based on the premise of dialogicality and heteroglossity of language. It focuses on the negotiation of interpersonal or ideational meaning, the rhetorical effect produced by the choice of stance and the expression of viewpoint (Martin \& White 2005). In addition, engagement not only expresses the orientation of the author's attitudes, but also reflects the mutual negotiation process of different social signs in the text. According toMartin \& White (2005), the engagement system provides the means to characterize a speaker/writer's interpersonal style according to what sort of heteroglossic backdrop of other voices. Through the engagement resources, the author accepts, acknowledges, responds, challenges, or opposes the speech of others, or expects the response from other aspects (Wang, 2010). The engagement system is divided into monogloss and heterogloss (Martin \& White, 2005). Monogloss is an intersubjective bare assertion, usually in a sure way to express a position or a point of view, while excluding other points of view. Heterogloss can be understood as the expression that indicates the possible existence of other points of view. The difference between them is that monogloss contains only one voice which is a universally agreed belief, while heterogloss refers to or conveys other voices or positions (Xin \& Wu, 2018). According to the degree of dialogic openness of the discourse, heterogloss can be divided into 
two categories: dialogic contraction and dialogic expansion. Dialogic contraction and expansion can be further divided into different sub-categories. The whole sub-categories of heterogloss are depicted in Figure 1.

Dialogic contraction is that the speaker shrinks space of conversation by means of "disclaim" and "proclaim", and then limits or rejects other viewpoints. "Disclaim" simply means that the speaker does not accept the viewpoints of others which are often substituted by the speaker's own points or limited by means of transitional words (e.g. although, however, yet, but) or evaluative words (e.g. even, only, just, surprisingly, amazingly). "Proclaim" challenges and restricts the current proposition by quoting the authoritative discourse of others, so as to make the reader identify with the discourse and narrow the dialogue space. "Disclaim" in the dialogic contraction includes "deny" and "counter". "Deny" is the author's presupposition that the reader has a viewpoint contrary to the current proposition, and the negotiation space is reduced by denying this viewpoint so as to realize the purpose of affirming the current proposition. "Counter" means that although the speaker has not directly denied it, he replaces the viewpoint with another unexpected one, thus causing the proposition to be controversial. "Proclaim" includes "concur", "pronounce", and "endorse". "Concur" indicates an opinion or description that is taken for granted without the need for an answer. It can be implemented utilizing evaluative words (e.g. naturally, obviously, of course, certainly, admittedly, not surprisingly), questions, and certain sentence structures (e.g. I accept that, however). "Pronounce” expresses the speaker's approval of the current proposition, indicating his or her attitude as an authority or subject. It can be realized by means of parentheses (e.g. I contend that..., the truth of the matter is that..., we can only conclude that..., you must agree that...), intensifiers (e.g. really, indeed), capitalizing certain words (e.g. The level of tolerance IS the result of government intervention). "Endorse" refers to those formulations by which propositions are constructed by the authorial voice as correct, valid, or maximally warrantable, often realized by some "factivity" words, such as show, prove, demonstrate, find, point out.

Dialogical expansion is to open up space for other viewpoints, including "entertain" and "attribute". "Entertain" implies that the proposition is but one of a number of possible positions and thereby makes dialogic space for those possibilities which can be assessed via modal auxiliaries (may, might, could, must, etc.), modal adjuncts ( perhaps, probably, definitely, etc.), via modal attributes (it’s possible that..., it’s likely that..., etc.), via circumstances of the "in my view" type, and via certain mental verb/attribute projections (I suspect that..., I think, I believe, I'm convinced that, I doubt, etc.)(Martin \& White, 2005). “Attribution” refers to the possibility of multiple propositions when the author expresses the internal authorial propositional by using an external voice. "Attribution" can be divided into "acknowledge" and "distance”. "Acknowledge” is neutral attribution, which means that the speaker expresses his views through a quotation by using reporting verbs such as say, report, state, declare, announce, believe, and think. "Distance" is to report the proposition without taking responsibility. It is most typically realized by means of the reporting verb (e.g. to claim) and by certain uses of "scare" quotes.

The materials analyzed in this paper are collected from the English versions of 20 regular press conferences from March to December 2019 (two for each month, respectively for the middle and the last ten days of each month) downloaded from the official website of the Ministry of Foreign Affairs of the People's Republic of China). The content only contains the information announced by the spokespersons and their response to the question raised by the journalists. There are a total of 25,894 tokens. Corpus analysis software AntConc was used to conduct quantitative analysis under the framework of the engagement system. The occurrence frequency of each type of engagement resources was counted. Then qualitative analysis was 
conducted on the distribution of engagement resources with specific examples to explore how the spokespersons express their stance.

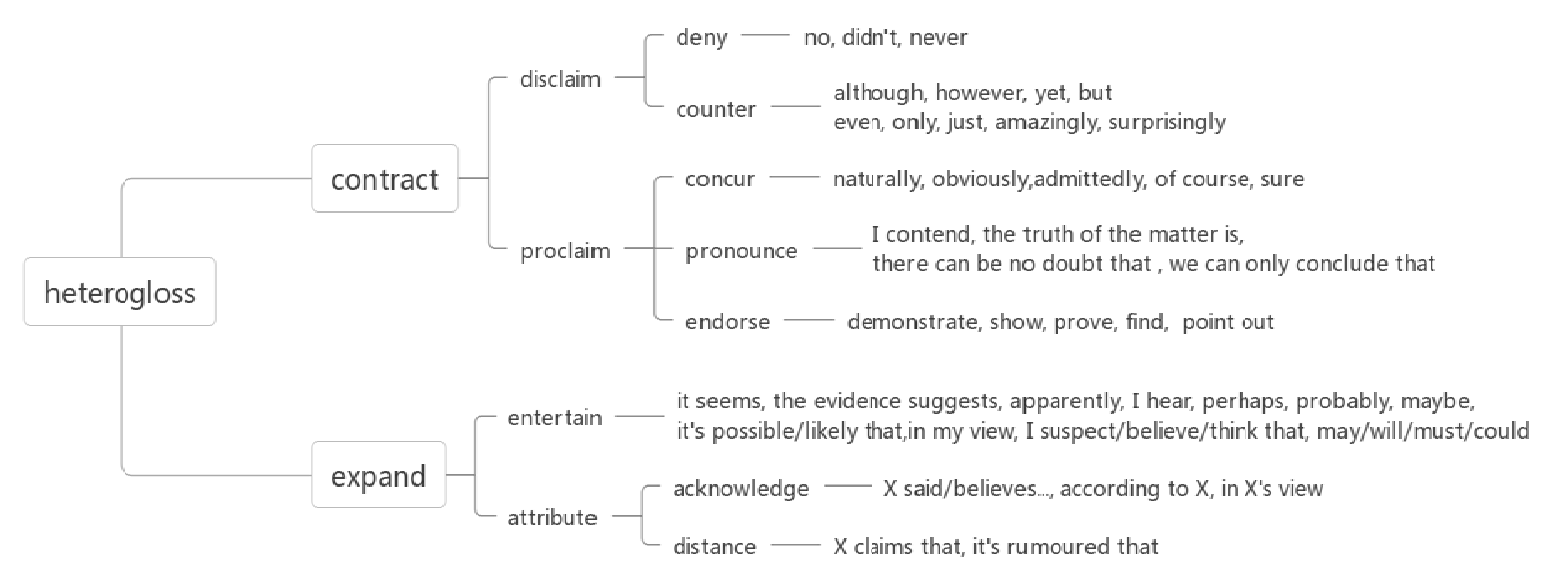

Figure 1. Engagement: heterogloss.

\section{General Distribution of Engagement Resources}

Statistical results show that there are 671 tokens of engagement resources in 20 English versions of regular press conference reports, including 253 (37.70\%) tokens of dialogic contraction and 418 (62.30\%) tokens of dialogic expansion, which are specifically shown in Tables 1 and 2 . It clearly shows that the spokesperson used various engagement resources to negotiate with listeners, and we can infer that dialogic expansion is almost two times more than dialogic contraction, as can be seen from Table 1.

Table 1

Distribution of Dialogic Contraction

\begin{tabular}{llllll}
\hline \multirow{2}{*}{ Category } & \multicolumn{5}{c}{ Contract 253 (37.70\%) } \\
\cline { 2 - 6 } & Deny & Counter & Concur & Proclaim 42(16.60\%) \\
Amount & 117 & 94 & 2 & 6 & Pronounce \\
Frequency & $55.45 \%$ & $44.55 \%$ & $4.76 \%$ & $14.29 \%$ & 34 \\
\hline
\end{tabular}

“disclaim” resources have 211 tokens, occupying $83.40 \%$ of all contraction resources, while "proclaim” 42 tokens, accounting for $16.60 \%$. This can indicate that "disclaim" resources are chosen in preference to "proclaim" resources when the spokesperson tries to contract the dialogic space. "Disclaim" includes "deny" and "counter". "Deny" resources have 117 tokens, taking up 55.45\% of all disclaim resources. "Counter" resources have 94 tokens, occupying $44.55 \%$ of disclaim resources. These data indicate that "deny" resources are a little more frequently used when the spokesperson tends to disclaim a proposition. "Proclaim" resource, including concur, pronounce, and endorse, not only in the overall frequency is much lower than "deny" resource, but also the use of and distribution of its sub-category is extremely uneven. "Endorse" resources have occurred 34 times, while pronounce resources 6 times, and concur resources 2 times, taking up 80.95\%, 14.29\%, $4.76 \%$ respectively of all proclaim resources. We can see that the absolute majority of "proclaim" is realized through endorse resources. Table 2 shows the distribution of dialogic expansion. "Entertain" resources have 
322 tokens, occupying $77.03 \%$ of all expansion resources, while "attribute" resources have 96 tokens. Within the "attribute", there are "acknowledge” and "distance" resources occurring 94 times and 2 times respectively. In conclusion, engagement resources are frequently used by the spokesperson in the regular press conferences. On the whole, the spokesperson is more inclined to use dialogic expansion resources which reserve a larger space for communication and allow journalists to express different positions and views when asking questions. The use of dialogic expansion resources is also conducive to the spokesperson's understanding of the concerns and attitudes of domestic and foreign journalists on China's diplomacy. In the following, we will combine examples to interpret and discuss the above statistical results in a more specific way.

Table 2

Distribution of Dialogic Expansion

\begin{tabular}{llll}
\hline \multirow{2}{*}{ Category } & \multicolumn{3}{c}{ Expand 418 (62.30\%) } \\
\cline { 2 - 4 } & Entertain 322(77.03\%) & Actribute 96(22.97\%) \\
\cline { 3 - 4 } & 322 & 94 & Distance \\
\hline Amount & $100 \%$ & $97.92 \%$ & 2 \\
Frequency & & $2.08 \%$ \\
\hline
\end{tabular}

\section{Dialogic Contraction}

In the dialogic contraction resources, the proportion of "disclaim" resources is very high(83.40\%). The spokesperson likes to negate some propositions directly in order to limit or reduce the conversation space. Inside the negation resources (117 tokens), "no" (33 tokens) and "not” (71 tokens) are used frequently. For example, when referring to the interference in Chinese internal affairs, the use of "deny" resources is quite common:

[1]He is in no (deny) position to make wanton comments on China-US relations. China's position on issues regarding Hong Kong and China-US trade consultations is consistent and clear. I will reiterate that Hong Kong affairs are purely China's internal affairs. No (deny) foreign government, organization, or individual has any right to interfere.(2019.9.16)

[2]Hong Kong is a special administrative region (SAR) of China and its affairs are purely China's internal affairs that brook no (deny) foreign interference. (2019.6.14)

The Hong Kong issue was mentioned in Examples 1 and 2. The spokesperson directly negated the stand and views of other countries or other people who wanted to interfere in China's internal affairs. He adopted a tough attitude and directly closed off the space for dialogue. He stressed that the Hong Kong issue was an internal issue and China's sovereignty was beyond doubt. Other countries should have no illusions about it.

Another finding from the AntConc search,which was that "I'm not aware of", is often used by spokesperson when there is no clear answer to a question. For example:

I'm not (deny) aware of what you said. But(counter resource) since you mentioned Xinjiang, as I said earlier, our measures on counter-terrorism and de-radicalization have been effective in Xinjiang, and our policies are endorsed by all ethnic groups. (2019.7.15)

I'm not (deny) aware of what you said and I'd like to refer you to the military. (2019.8.19)

The speech of the Foreign Ministry spokesperson represents the position and attitude of the country. Consequently, in the face of uncertain issues, directly restricting the dialogue space by "deny" resources makes the speech more rigorous and shows China's responsible attitude. 
"Proclaim" resource is used less than "deny" in dialogic contraction, and the more common resource of it is the endorse resource. Speakers narrow the conversation space by using the endorse resource to indicate the accuracy and authority of the external voice. For example:

[5]Facts speak louder than words and people can tell right from wrong. History has proven and will continue to prove that China's development is an opportunity for the world and China is always an architect of world peace, contributor to global development, and champion of international order. This cannot be vilified by any country or individual. (2019.9.16)

[6]As the ambassadors pointed out, those who had visited Xinjiang found what they saw was completely different from what was described in Western media reports. (2019.7.15)

In example 5, the spokesperson uses history as a witness to support his view; in example 6, the spokesperson indirectly quotes an ambassador's words who has been to Xinjiang himself to confirm the false reports about Xinjiang in west media. On the one hand, it can increase the credibility of his position, on the other hand, reduce the possibility of other views.

\section{Dialogic Expansion}

The use of dialogic expansion resources is far greater than that of dialogic contraction resources. In general, the spokesperson wants to expand and open up the communication space through regular press conferences, which is also conducive to promoting interaction between the speaker and journalists. The use of entertain resources is very frequent. The entertain resources are used to express personal opinions, but imply that it is only one of many positions, thus opening up dialogue space. Among the 322 entertain resources, the use of modal verbs accounts for 299 times, of which "will” appears 258 times. Through the retrieval of AntConc, the frequent co-occurrence clusters with "will” include "will continue”, "will hold”, "will pay”, "will meet” and so on, while "we” and "China” are the most frequent subjects of "will”. For example:

[7]We will continue to forge ahead on the path of socialism with Chinese characteristics and make new strides along the way. (2019.3.14)

[8]China will continue to work with other developing countries to uphold the UN-centered international order based on international law. We will joint steer the world in the right direction of mutual respect, fairness, justice and win-win cooperation. (2019.7.30)

It is clear that the spokesperson makes expectations of the country's further work deployment, rather than assertions, thus leaving more space for dialogue. Instead of directly resistance, the modality "will” gives us a way of offering information in a moderate manner which indicates that the proposition is an obligation rather than a command so as to keep the alignment with the audience.

Attribution resources are used much less frequently than entertain resources. Attribute is the process of attributing a proposition to an external source by separating it from the internal voice of the text through the use of direct and indirect speeches. Spokesperson prefers to refer to "acknowledge" resources. For example:

[9]After the Hong Kong SAR government announced the suspension of the amendment bill on June 15, the Central Government stated that it supports, respects and understands the decision. (2019.8.30)

With regard to the Hong Kong's legislative amendment, the spokesperson using the "acknowledge" resources, does not indicate whether his voice is on the side of the proposition, or whether he remains neutral or disinterested on the proposition. As a result, the proposition is obviously subjective and personal. It leaves 
room for possible different viewpoints. It also shows that the Central Government holds an active and positive attitude in talking with the violent elements in Hong Kong.

\section{Conclusion}

By analyzing the intervention resources in 20 regular press conference reports of Foreign Ministry spokespersons, this paper finds that spokespersons use more dialogic expansion resources, which shows that spokespersons are willing to reserve dialogue space for different views while expressing their stance. In some cases, dialogic contraction resources are frequently used, such as the use of "deny" resources to strengthen the unquestionable position of sovereignty by narrowing the dialogue space, and the use of "deny" resources to narrow the dialogue space when facing uncertain questions. The use of modal verbs is an important means of dialogic expansion. The speaker uses a large number of dialogic resources to show China's position to the world, and also reveals that China is willing to build a dialogue space of equal consultation, harmony, and inclusiveness. This paper only analyzes the distribution of engagement resources. The attitude resources and graduation resources of appraisal theory will also have an impact on the expression of positions and views, hence further research can be conducted comprehensively and systematically by analyzing those three resources.

\section{References}

Martin, J. R., \& Rose, D. (2002). Working with discourse: Through context, beyond the clause. London: Continuum.

Martin, J. R., \& White, P. R. R. (2005). The language of evaluation: Appraisal in English. London: Palgrave MacMillan.

Wang, Z. H. (2001). Appraisal systems and their operation:A new development in the systemic functional linguistics. Journal of Foreign Languages, 6, 13-20.

White, P. R. R. (2003). Beyond modality and hedging: A dialogic view of the language of intersubjective stance. Text: Special Issue on Negotiating Heteroglossis, 23, 259-284.

Wu, Y. (2011). Research on the agenda-setting effect of Chinese discourses:A case study on foreign ministry spokesperson. World Economics and Politics, 2, 16-39, 156-157.

Xin, B., \& Wu, L. L. (2018). An analysis of engagement resources in the Sino-American media reports on the belt and road initiative. Foreign Languages Research, 35, 1-7, 112.

Zhang, Q. M., \& Yang, L. Z. (2017). China’s diplomatic transformation and institutional innovation. Foreign Affairs Review, 34, 22-53. 